\title{
ANALISIS NILAI TAMBAH DAN STRATEGI PENGEMBANGAN USAHA KOPI (Coffea, $s p$ ) DI KELOMPOK TANI HUTAN (KTH) CIBULAO HIJAU
}

\author{
RN. Tamaradewi ${ }^{1 \mathrm{a}}$, H. Miftah ${ }^{1}$ dan A. Yoesdiarti ${ }^{1}$ \\ ${ }^{1}$ Jurusan Agribisnis, Fakultas Pertanian Universitas Djuanda Bogor \\ Jalan Tol Ciawi No. 1 Kotak Pos 35 Bogor 16720 \\ ${ }^{a}$ Korespondensi: R. Nadya Tamaradewi, Email: nadya.tamaradewi.z@unida.ac.id
}

\begin{abstract}
ABSTRAK
Penelitian ini bertujuan untuk mengetahui nilai tambah kopi Robusta dan Arabika di KTH Cibulao Hijau, mengidentifikasi faktor internal dan eksternal yang mempengaruhi pengembangan usaha kopi di KTH Cibulao Hijau, serta menentukan pilihan strategi alternatif dan prioritas strategi yang dapat diterapkan dalam pengembangan usaha kopi di KTH Cibulao Hijau. Analisis data menggunakan analisis nilai tambah metode Hayami dan analisis strategi pengembangan usaha dengan tiga tahap formulasi strategi. Pemilihan responden dilakukan secara purposive sampling. Jumlah responden nilai tambah 3 orang dan responden strategi pengembangan berasal dari internal dan eksternal KTH Cibulao Hijau. Nilai tambah paling tinggi yang dihasilkan dari proses pengolahan kopi Robusta adalah Robusta dengan Natural process dengan nilai tambah green bean, roasted bean dan kopi bubuk yaitu Rp 5.510 (42,38\%), Rp 77.781 (52,55\%), dan Rp 159.821 (45,66\%) . Nilai tambah tertinggi yang dihasilkan dari proses pengolahan kopi Arabika adalah Arabika dengan Full wash process dengan nilai tambah green bean, roasted bean dan kopi bubuk yaitu Rp 3.735 (26,12\%), Rp 182.091 (63,45\%), Rp $84.548(18,79 \%)$. Analisis matriks IFE menghasilkan total skor 2,708 dan analisis matriks EFE menghasilkan total skor 2,911. Alternatif strategi yang dihasilkan ada 7 pilihan dari matriks SWOT dan prioritas strategi yang dipilih berdasarkan matriks QSPM yaitu meningkatkan kompetensi SDM dan kualitas dalam manajerial dalam kelompok dengan nilai STAS 6,55
\end{abstract}

Kata Kunci: Kopi Robusta, Kopi Arabika, Nilai Tambah, Strategi Pengembangan

\section{PENDAHULUAN}

Kopi telah menjadi kebutuhan bagi sebagian masyarakat seiring dengan meningkatnya gaya hidup. Perlakuan pengolahan kopi bagi pelaku usaha dapat meningkatkan harga jual dan keuntungan yang diperoleh (Badan Pusat Statistik, 2017).

Jawa Barat merupakan salah satu Provinsi di Indonesia dengan beberapa daerah sebagai penghasil kopi. Produksi kopi di Jawa Barat tahun 2017 sebanyak 18.123 ton (Badan Pusat Statistik, 2017).

Kabupaten Bogor menjadi salah satu daerah produksi kopi di Jawa Barat dengan jumlah produksi terbesar kedua setelah
Kabupaten Bandung. Jumlah produksi kopi tahun 2017 sebanyak 2.969 ton (BPS Jawa Barat, 2018).

Kopi Bogor sedang menjadi primadona sektor pertanian Kabupaten Bogor karena banyak prestasi yang diraih baik nasional maupun internasional (Pemerintah Kabupaten Bogor, 2019). Kopi yang diusahakan sebagian besar kopi rakyat jenis Robusta dan Arabika yang tersebar di beberapa kecamatan (Balai Penelitian Tanaman Industri dan Penyegar, 2018).

Kecamatan Cisarua adalah salah satu kecamatan di Kabupaten Bogor sebagai penghasil kopi Robusta dan Arabika dengan jumlah produksi tahun 2018 yaitu $9.625 \mathrm{~kg}$ 
(Dinas Tanaman Pangan Hortikultura dan Perkebunan Kabupaten Bogor, 2018)

Kecamatan Cisarua memiliki jumlah produksi kopi yang tidak terlalu besar dibandingkan kecamatan lain di Kabupaten Bogor namun kopi yang dihasilkan memiliki kualitas baik dan permintaan yang relatif lebih tinggi. Salah satu kelompok yang melakukan produksi dan pengolahan kopi di Kecamatan Cisarua adalah Kelompok Tani Hutan (KTH) Cibulao Hijau.

Kelompok Tani Hutan (KTH) Cibulao Hijau merupakan kelompok di Kampung Cibulao Kecamatan Cisarua yang menjadi penghasil kopi kategori kopi spesialti. Kopi Cibulao memiliki kondisi lingkungan mendukung yang menghasilkan cita rasa khas sebagai keunggulan dan permintaan yang terus bertambah namun jumlah produksi belum mampu memenuhi kebutuhan pasar.

Kopi dipasarkan dalam bentuk green bean, roasted bean dan kopi bubuk yang menghasilkan nilai tambah yang dapat diketahui untuk melihat adanya alternatif pilihan proses pengolahan yang dapat menghasilkan keuntungan maksimal.

Potensi Kopi Cibulao terlihat dari adanya keunggulan kopi Robusta yang pernah meraih juara pertama dalam Kontes Kopi Spesialti Indonesia (KKSI) di Aceh tahun 2016 (Balai Penelitian Tanaman Industri dan Penyegar, 2018).

Potensi yang cukup tinggi menjadi peluang KTH Cibulao Hijau untuk melakukan pengembangan usaha sehingga perlu mengidentifikasi faktor internal dan eksternal yang dimiliki. KTH Cibulao Hijau memiliki banyak keunggulan dan peluang namun belum ditunjang dengan pengelolaan internal kelompok yang optimal. Faktor internal dan eksternal perlu diperhatikan untuk merumuskan strategi yang tepat bagi pengembangan usaha.

Penelitian ini bertujuan untuk mengetahui nilai tambah kopi Robusta dan
Arabika, mengidentifikasi kondisi faktor internal dan faktor eksternal yang mempengaruhi pengembangan usaha kopi di KTH Cibulao Hijau dan menentukan pilihan strategi alternatif dan prioritas strategi yang dapat diterapkan dalam pengembangan usaha kopi di KTH Cibulao Hijau.

\section{BAHAN DAN METODE}

\section{Lokasi dan Waktu Penelitian}

Penelitian dilakukan di KTH Cibulao Hijau yang berlokasi di Kampung Cibulao Desa Tugu Utara Kecamatan Cisarua. Pemilihan lokasi secara sengaja (purposive) dengan pertimbangan salah satu kelompok penghasil dan pengolahan kopi dengan kategori kopi spesialti di Kabupaten Bogor. Penelitian dilakukan bulan Juli sampai Agustus 2019.

\section{Jenis dan Sumber Data}

Data yang digunakan adalah data primer dan data sekunder. Data primer diperoleh melalui kuesioner dan wawancara dengan responden yang telah ditentukan. Data sekunder merupakan data pendukung yang diperoleh dari literatur dan sumber lain berkaitan dengan topik penelitian.

\section{Metode Pengambilan Responden}

Pengambilan responden dilakukan secara purposive sampling. Responden untuk nilai tambah yaitu pengurus KTH Cibulao Hijau yang merupakan ketua, wakil ketua dan sekretaris. Responden untuk strategi pengembangan terdiri dari pihak internal dan pihak eksternal. Pihak internal berjumlah dua orang yaitu ketua dan wakil ketua KTH Cibulao Hijau. Pihak eksternal yaitu Ketua RT Kampung Cibulao, Bagian Teknis Desa Tugu Utara, Penyuluh Pertanian Lapangan dari KTH Cibulao Hijau dan kedai kopi sebagai konsumen.

\section{Metode Analisis Data}

Metode analisis data menggunakan metode Hayami untuk nilai tambah dan strategi pengembangan usaha menggunakan 
tiga tahap formulasi strategi. Data primer diolah menggunakan Microsoft Excel 2013.

\section{Analisis Nilai Tambah}

Analisis nilai tambah digunakan untuk melihat besar nilai tambah yang dihasilkan dari produk kopi dan ditentukan dengan menggunakan metode Hayami (Hayami, 1987).

\section{Analisis Strategi Pengembangan Usaha}

Analisis strategi pengembangan usaha kopi dilakukan menggunakan tiga tahap formulasi strategi (David, 2016) :

1. Tahap Masukan (Input)

Tahap input dilakukan untuk mengidentifikasi lingkungan faktor internal dan faktor eksternal di KTH Cibulao Hijau. Tahap input terdiri dari matriks IFE untuk faktor internal (kekuatan dan kelemahan) dan matriks EFE untuk faktor eksternal (peluang dan ancaman).

2. Tahap Pencocokan

Tahap pencocokan menggunakan matriks IFE dan matriks EFE untuk menghasilkan beberapa alternatif strategi. Tahap ini terdiri dari matriks IE yang memiliki sembilan kuadran dengan melihat hasil skor tertimbang (IFE dan EFE) dan matriks SWOT yang memiliki empat strategi utama yaitu SO, ST, WO, WT.

3. Tahap Keputusan

Tahap keputusan dilakukan dengan matriks QSPM yang menggunakan faktor internal dan eksternal kunci untuk mendapatkan prioritas strategi melalui nilai STAS.

\section{HASIL DAN PEMBAHASAN}

\section{Analisis Nilai Tambah Kopi di KTH Cibulao Hijau}

Jenis proses olahan kopi ada tiga yaitu Natural, Honey dan Full wash. Perbedaan terdapat pada urutan tahap proses setelah kopi di panen seperti yang diuraikan sebagai berikut :
1. Pengolahan secara Natural process, memiliki tahapan pengolahan yaitu:
a. Penjemuran buah cherry kopi
b. Pelepasan kulit kopi
c. Sortasi biji kopi

2. Pengolahan secara Honey process, memiliki tahapan pengolahan yaitu :
a. Pelepasan kulit buah cherry kopi
b. Penjemuran buah kopi
c. Pelepasan kulit gabah
d. Sortasi biji kopi

3. Pengolahan secara Full wash process, memiliki tahapan yaitu :

a. Pelepasan kulit buah kopi

b. Perendaman biji kopi

c. Pelepasan kulit gabah kopi

d. Sortasi biji kopi

Tahap setelah sortasi untuk semua jenis olahan yaitu proses roasting, proses grinding, dan pengemasan. Perhitungan sumbangan input lain pada nilai tambah kopi Robusta dan Arabika terdapat pada Lampiran 1. Perhitungan nilai tambah kopi Robusta dan Arabika terdapat pada Lampiran 2.

\section{Analisis Nilai Tambah Kopi Robusta di KTH Cibulao Hijau}

Nilai tambah kopi di KTH Cibulao Hijau dihitung dengan menggunakan metode Hayami. Bahan baku awal yang digunakan di penelitian ini disamakan untuk semua jenis olahan baik Natural, Honey dan Fullwash yaitu $100 \mathrm{~kg}$ buah cherry kopi yang menghasilkan input green bean. Bahan baku untuk output roasted bean adalah green bean dan bahan baku untuk output kopi bubuk adalah roasted bean dengan jumlah masing-masing tergantung konversi yang dihasilkan.

\section{Kopi Robusta Natural process}

Input $100 \quad \mathrm{~kg}$ cherry kopi menghasilkan $20 \mathrm{~kg}$ green bean. Input $20 \mathrm{~kg}$ green bean menghasilkan $16 \mathrm{~kg}$ roasted bean. Input $16 \mathrm{~kg}$ roasted bean menghasilkan $16 \mathrm{~kg}$ kopi bubuk. Nilai 
tambah dari pengolahan setiap produk green bean, roasted bean dan kopi bubuk dengan Natural process adalah $\mathrm{Rp} 5.510, \mathrm{Rp}$ 77.781, dan $\mathrm{Rp} 159.821$ setiap $\mathrm{kg}$ produk yang dihasilkan. Rasio nilai tambah untuk masing-masing produk yaitu $42,38 \%$, $52,55 \%$ dan 45,66 \%. Tingkat keuntungan (Rp/kg) yang didapat dari setiap olahan masing-masing yaitu Rp. 2.640, Rp 52.369 dan Rp 158.321

\section{Kopi Robusta Honey process}

Input sejumlah $100 \mathrm{~kg}$ cherry kopi menghasilkan $20 \mathrm{~kg}$ ouput green bean. Input $20 \mathrm{~kg}$ green bean menghasilkan $16 \mathrm{~kg}$ roasted bean. Input $16 \mathrm{~kg}$ roasted bean menghasilkan $16 \mathrm{~kg}$ kopi bubuk. Nilai tambah setiap produk green bean, roasted bean dan kopi bubuk dengan Honey process adalah Rp 5.754, Rp77.749 dan Rp 159.792 .Rasio niliai tambah masing-masing produk yaitu $44,26 \%, 52,53 \%$, dan $45,65 \%$. Tingkat keuntungan yang didapatkan setiap olahan masing-masing adalah Rp 2.881, Rp 52.337 dan Rp 158.292

\section{Analisis Nilai Tambah Kopi Arabika di KTH Cibulao Hijau}

1. Kopi Arabika Natural process

Input cherry kopi sebanyak $100 \mathrm{~kg}$ menghasilkan $14,3 \mathrm{~kg}$ green bean. Input $14,3 \mathrm{~kg}$ green bean menjadi 11,4 kg roasted bean. Input $11,4 \mathrm{~kg}$ roasted bean menghasilkan 11,4 kg kopi bubuk. Nilai tambah setiap produk green bean, roasted bean dan kopi bubuk adalah Rp 8.324, Rp 163.035 dan Rp 74.548. Rasio nilai tambah setiap produk secara berurutan adalah $43,12 \%, 53,82 \%$ dan $16,21 \%$. Tingkat keuntungan $(\mathrm{Rp} / \mathrm{kg})$ yang diperoleh untuk masing-masing olahan yaitu $\mathrm{Rp} 6.235, \mathrm{Rp}$ 134.319 dan Rp 72.443

\section{Kopi Arabika Honey process}

Input $100 \mathrm{~kg}$ cherry kopi $100 \mathrm{~kg}$ menghasilkan green bean $14,3 \mathrm{~kg}$. Input green bean $14,3 \mathrm{~kg}$ menghasilkan roasted bean $11,4 \mathrm{~kg}$. Input roasted bean $11,4 \mathrm{~kg}$ menghasilkan kopi bubuk 11,4 kg. Nilai tambah produk green bean, roasted bean dan kopi bubuk masing-masing adalah Rp 5.709, Rp174.483 dan Rp 84.469. Rasio nilai tambah untuk setiap olahan secara berurutan adalah 34,7\%, 59,15\% dan $18,36 \%$. Tingkat keuntungan $(\mathrm{Rp} / \mathrm{kg})$ yang diperoleh dari setiap masing-masing olahan yaitu Rp 3.619, Rp 145.767 dan Rp 82.364

3. Kopi Arabika Full wash process

Input cherry kopi $100 \quad \mathrm{~kg}$ menghasilkan green bean sebanyak 14,3 kg. Input green bean 14,3 kg menghasilkan 11,4 $\mathrm{kg}$ roasted bean. Input roasted bean $11,4 \mathrm{~kg}$ menghasilkan 11,4 kg kopi bubuk. Nilai tambah produk green bean, roasted bean dan kop bubuk secara berurutan adalah $\mathrm{Rp}$ 3.735, Rp 182.091, Rp 84.548. Rasio nilai tambah setiap produk secara berurutan adalah 26,12\%, 63,45\% dan 18,79\%. Tingkat keuntungan $(\mathrm{Rp} / \mathrm{kg})$ dari masingmasing olahan yaitu $\mathrm{Rp} 1.644, \mathrm{Rp} 153.375$ dan $\operatorname{Rp} 82.443$.

\section{Strategi Pengembangan Usaha Kopi di KTH Cibulao Hijau}

\section{Identifikasi Lingkungan Internal KTH Cibulao Hijau}

Lingkungan internal KTH Cibulao Hijau secara lebih rinci dijelaskan sebagai berikut :

1. Manajemen

Penerapan fungsi manajemen KTH Cibulao Hijau dapat dilihat lebih jelas sebagai berikut :

a. Perencanaan : belum ada perencanaan jangka panjang secara lebih spesifik

b. Pengorganisasian : ada struktur organisasi namun belum berjalan sebagaimana mestinya.

c. Pemberian motivasi : anggota yang berhasil melakukan produksi kopi akan mendapat keuntungan tambahan dari penjualan kopi. 
d. Penempatan karyawan : pengurus kelompok belum melakukan fokus pekerjaan sesuai dengan bagiannya secara optimal

e. Pengendalian : evaluasi belum dilakukan secara lebih mendalam.

2. Produksi

Produksi olahan kopi menggunakan bahan baku buah cherry kopi dari anggota kelompok yang ditanam sebagai tujuan utama konservasi hutan. Kegiatan produksi masih dilakukan oleh beberapa orang karena sumberdaya manusia yang terbatas.

3. Pemasaran

a. Saluran pemasaran kopi di KTH Cibulao Hijau yaitu :

Saluran 1 : KTH Cibulao Hijau Roastery (40\%)

Saluran 2 : KTH Cibulao Hijau - Kedai kopi (30\%)

Saluran 3 : KTH Cibulao Hijau - Hotel $(15 \%)$

Saluran 4 : KTH Cibulao Hijau Konsumen akhir (10\%)

Saluran 5 : KTH Cibulao Hijau Pedagang Pengumpul (5\%)

b. Bauran Pemasaran

1) Produk : Kopi yang dihasilkan adalah jenis kopi spesialti baik Robusta (fine Robusta) dan Arabika (Arabica specialty) dengan tiga proses olahan yaitu Natural, Honey dan Full wash dalam bentuk green bean, roasted bean dan kopi bubuk.

2) Harga : Produk kopi robusta dan arabika memiliki harga yang berbedabeda tergantung jenis proses olahan dan bentuk produk yang dijual. KTH Cibulao Hijau berperan sebagai price maker dalam penentuan harga jual.

3) Tempat/Distribusi :Produk kopi dipasarkan secara langsung di lokasi produksi dan beberapa tempat lain. Wilayah cakupan pemasaran yaitu Bogor dan Jabodetabek.
4) Promosi : Promosi yang dilakukan antara lain mengikuti kegiatan pameran kopi dan media sosial namun belum optimal.

\section{Keuangan}

Kelompok tidak memiliki sistem gaji bagi pengurus kelompok. Pencatatan keuangan masih belum dilakukan.

5. Penelitian dan Pengembangan

KTH Cibulao Hijau selain dalam hal produk sedang berusaha mengembangkan usahanya dalam hal mengoptimalkan pemanfaatan potensi wisata yang dimiliki.

6. Sistem Informasi Manajemen

KTH Cibulao Hijau belum menerapkan sistem informasi manajemen kelompok secara tertulis sehingga informasi mengenai usaha yang dijalankan hanya dapat diperoleh melalui keterangan dari pengurus atau anggota..

\section{Identifikasi Lingkugan Eksternal KTH Cibulao Hijau}

Lingkungan eksternal KTH Cibulao Hijau secara lebih rinci dijelaskan sebagai berikut :

\section{Kekuatan Ekonomi}

Pelaku usaha yang semakin meningkat di suatu daerah dapat menjadi potensi ekonomi bagi daerah tersebut. Kenaikan harga kopi relatif stabil dan tidak fluktuatif.

2. Kekuatan sosial, budaya dan lingkungan

Keberadaan KTH Cibulao Hijau di kampung Cibulao diharapkan dapat memberikan dampak sosial bagi masyarakat sekitar. Kondisi lingkungan seperti cuaca tidak stabil mempengaruhi hasil produksi dan pengolahan kopi.

3. Kekuatan politik, pemerintahan dan hukum

Kelompok mendapatkan bantuan berupa bibit, mesin pengolahan dan juga pembinaan dari penyuluh lapangan. Kelompok juga mendapat izin pengelolaan lahan dari Perhutani. 


\section{Teknologi}

Teknologi mesin pengolahan kopi dengan kapasitas yang lebih besar dan teknologi informasi menjadi hal yang perlu diperhatikan kedepannya.

5. Kompetitif

Kondisi pesaing kopi baik Kopi Bogor sebagai maupun kopi spesialti dari wilayah lain yang lebih luas cukup banyak.

\section{Identifikasi Faktor Internal yang dimiliki KTH Cibulao Hijau}

\section{Kekuatan}

a. Jenis kopi spesialti dengan kualitas baik dan cita rasa khas

b. Harga jual yang tinggi

c. Jenis proses olahan yang beragam

d. Peralatan dan teknologi yang digunakan cukup memadai

e. Memiliki brand image yang dikenal di masyarakat khususnya penggemar kopi

f. Pemberdayaan masyarakat sekitar sebagai SDM di kelompok

g. Lokasi usaha strategis

h. Memiliki beberapa pelanggan tetap

i. Penanaman kopi berbasis konservasi

2. Kelemahan

a. Belum memiliki PIRT dan Sertifikasi Halal

b. Jumlah produksi dan pasokan belum bisa memenuhi permintaan

c. Modal yang terbatas

d. Pengelolaan sistem manajerial kelompok belum optimal

e. Akses jalan menuju lokasi kurang memadai

f. Sumberdaya manusia kelompok masih terbatas dan belum terlatih secara optimal

g. Kegiatan promosi belum optimal

\section{Identiikasi Fkator Eksternal yang dimiliki KTH Cibulao Hijau}

1. Peluang

a. Kebutuhan dan permintaan kopi terus meningkat

b. Pasar kopi spesialti terbuka luas c. Potensi pengembangan usaha edukasi kopi masih terbuka luas

d. Teknologi informasi yang semakin canggih

e. Potensi lahan penanaman cukup luas

f. Teknologi pengolahan kopi yang semakin canggih

g. Semakin banyak petani yang menanam kopi

h. Banyak pelatihan terkait kualitas produksim manajerial dan pemasaran

2. Ancaman

a. Ada pesaing kopi baik kopi Bogor dan kopi spesialti dari daerah lain

b. Cuaca tidak stabil menyebabkan produksi dan kualitas terganggu

c. Kurangnya kesadaran masyarakat tentang perbedaan dan kualitas kopi spesialti

d. Jangkauan proses jual beli produk yang terbatas tanpa legalitas produk.

\section{Analisis Matriks IFE dan EFE}

\section{Matriks IFE}

Hasil matriks IFE menunjukkan kekuatan utama yang dimiliki KTH Cibulao Hijau adalah jenis kopi spesialti dengan kualitas baik dan cita rasa khas dengan skor 0,283 . Kelemahan utama yang dimiliki yaitu pengelolaan sistem manajerial kelompok yang belum optimal dengan skor 0,099 . Hail faktor internal menunjukkan total skor 2,708 .

2. Matriks EFE

Hasil matriks EFE menunjukkan peluang terbesar adalah permintaan kopi terus meningkat dengan skor 0,361. Ancaman yang terbesar adalah cuaca tidak stabil menyebabkan produksi dan kualitas terganggu dengan skor 0,095. Hasil faktor eksternal menunjukkan total skor 2,911.

\section{Analisis Matriks Internal Eksternal}

Hasil analisis matriks IE menunjukkan bahwa usaha kopi yang dijalankan berada 
pada kuadran $\mathrm{V}$ yang berarti jaga dan pertahankan.

Analisis matriks IE yang berada di kuadran $\mathrm{V}$ menunjukkan strategi yang tepat diterapkan di KTH Cibulao Hijau adalah penetrasi pasar. Upaya yang dapat dilakukan yaitu peningkatan kegiatan promosi degan memanfaatkan teknologi informasi yang semakin canggih dan menambah tenaga pemasaran yang fokus di kegiatan pemasaran

\section{Analisis Matriks SWOT}

Matriks SWOT menghasilkan beberapa alternatif strategi untuk pengembangan usaha yang dapat dilihat pada Lampiran. Hasil matriks SWO dijelaskan sebagai berikut :

1. Strategi SO

Mengoptimalkan pengembangan usaha kopi dan wisata edukasi dengan teknologi informasi dan pengolahan yang semakin canggih

2. Strategi ST

a. Mempertahankan dan meningkatkan kualitas olahan kopi

b. Mengoptimalkan pengelolaan kopi berbasis konservasi sebagai nilai jual dan positioning.
3. Strategi WO

a. Perbaikan dan peningkatan sistem perencanaan pemasaran dan memperkuat promosi

b. Meningkatkan kompetensi sumberdaya manusia dan kualitas manajerial dalam kelompok

c. Memperbanyak mitra kerja dengan lembaga lainnya dan mempertahankan kemitraan yang telah terjalin

\section{Strategi WT}

Memperkuat produk dengan legalitas usaha dan menjalin hubungan baik dengan pelanggan agar terbentuk loyalitas konsumen.

\section{Analisis Matriks QSPM}

Hasil prioritas strategi untuk pengembangan usaha kopi terdapat pada Tabel 1.

Hasil matriks QSPM menunjukkan alternatif strategi yang memiliki nilai STAS tertinggi adalah meningkatkan kompetensi sumberdaya manusia dan kualitas manajerial dalam kelompok dengan nilai STAS yaitu 6,55

Tabel 1 Matriks QSPM dalam Pengembangan Usaha Kopi di KTH Cibulao Hijau

\begin{tabular}{|l|l|l|}
\hline No & Alternatif Strategi & STAS \\
\hline 1 & $\begin{array}{l}\text { Meningkatkan kompetensi sumberdaya manusia dan kualitas manajerial dalam } \\
\text { kelompok. }\end{array}$ & 6,55 \\
\hline 2 & $\begin{array}{l}\text { Memperkuat produk dengan legalitas usaha dan menjalin hubungan baik } \\
\text { dengan pelanggan agar terbentuk loyalitas konsumen. }\end{array}$ & 6,34 \\
\hline 3 & $\begin{array}{l}\text { Perbaikan dan peningkatan sistem pemasaran dan memperkuat promosi } \\
\text { Mengoptimalkan pengembangan usaha kopi dan wisata edukasi dengan } \\
\text { teknologi informasi dan pengolahan yang semakin canggih }\end{array}$ & 6,26 \\
\hline 5 & $\begin{array}{l}\text { Memperbanyak mitra kerja dengan lembaga lain dan mempertahankan } \\
\text { kemitraan yang terjalin }\end{array}$ & 6,12 \\
\hline 6 & $\begin{array}{l}\text { Mempertahankan dan meningkatkan kualitas olahan kopi } \\
\text { Mengoptimalkan pengelolaan kopi berbasis konservasi sebagai nilai jual dan } \\
\text { positioning. }\end{array}$ & 5,10 \\
\hline
\end{tabular}




\section{KESIMPULAN DAN IMPLIKASI KEBIJAKAN}

\section{Kesimpulan}

Berdasarkan hasil pembahasan dapat disimpulkan bahwa :

1. Nilai tambah kopi Robusta lebih besar dibandingkan Arabika. Nilai tambah kopi Robusta paling besar yaitu Natural process dengan nilai tambah dan rasio nilai tambah masing-masing produk green bean, roasted bean dan kopi bubuk adalah Rp 5.510 (42,38\%) , Rp 77.781 (52,55\%), dan Rp $159.821(45,66 \%)$. Nilai tambah kopi Arabika paling besar yaitu Full wash process dengan nilai tambah dan rasio nilai tambah masingmasing produk adalah Rp 3.735 (26,12\%) , Rp $182.091(63,45 \%)$, Rp 84.548 $(18,79 \%)$.

2. KTH Cibulao Hijau memiliki faktor internal dengan total skor 2,708 dengan kekuatan utama yaitu jenis kopi spesialti dengan kualitas yang baik dan cita rasa khas serta kelemahan utama yaitu pengelolaan sistem manajerial kelompok yang belum optimal. Faktor eksternal yang ada memiliki total skor 2,911 dengan peluang terbesar adalah kebutuhan dan permintaan kopi yang terus meningkat serta ancaman utama yaitu cuaca yang tidak stabil menyebabkan produksi dan kualitas terganggu.

3. Ada 7 alternatif strategi yang dihaslkan dari matriks SWOT. Prioritas strategi yang dihasilkan dari matriks QSPM dengan nilai STAS tertinggi yaitu meningkatkan kompetensi sumberdaya manusia dan kualitas manajerial dalam kelompok, memperkuat produk dengan legalitas usaha dan menjalin hubungan baik dengan pelanggan agar terbentuk loyalitas konsumen, perbaikan dan peningkatan sistem pemasaran dan promosi, mengoptimalkan pengembangan usaha kopi dan wisata edukasi, memperbanyak mitra kerja dan mempertahankan kemitraan yang ada, meningkatkan kualitas olahan kopi, dan mengoptimalkan pengelolaan kopi berbasis konservasi sebagai nilai jual dan positioning.

\section{Implikasi Kebijakan}

1. KTH Cibulao Hijau dapat memaksimalkan keuntungan yang di dapat dari nilai tambah serta meningkatkan produksi pada setiap produk baik Robusta dan Arabika

2. KTH Cibulao Hijau dapat mempertahankan dan mengotimalkan proses olahan Arabika Full wash untuk pengolahan di musim hujan karena memiliki nilai tambah tinggi

3. KTH Cibulao Hijau dapat mempertimangkan penerapan strategi alternatif yang dihasilkan untuk pengembangan usaha kedepannya terutama prioritas strategi dengan nilai STAS tertinggi yaitu peningkatan kompetensi sumberdaya manusia dan manajerial karena menjadi hal yang sangat penting dalam pengembangan usaha

\section{Daftar Pustaka}

[Badan Pusat Statistik]. 2017. Statistik Kopi Indonesia 2017. Jakarta : BPS

[Balai Penelitian Tanaman Industri dan Penenyegar]. 2018. Kabupaten Bogor Bergairah Mengembangkan Kopi Robusta. Balitri.litbang.pertanian.go.id/. Diakses 20 Mei 2019

[Dinas Tanaman Pangan Hortikultura dan Perkebunan Kabupaten Bogor]. 2018. Laporan Rekapitulasi Luas Areal dan Produksi Pekebunan Rakyat TanamanTahunan Kabupaten Bogor. Bogor : Distanhorbun Kabupaten Bogor

[Pemerintah Kabupaten Bogor]. 2019. Pameran Agro dan Kopi Bogor-Bogor Fest 2019 dalam Rangka Gebyar Panca Karsa dan Program 100 Hari. 
http://bogorkab.go.id. Diakses 21 Juni 2019.

David FR dan David FR. 2016. Manajemen Strategik : Suatu Pendekatan Keunggulan Bersaing. Salemba Empat. Yogyakarta.
Hayami Y, et al. 1987. Agricultural Marketing and Processing in Upland Java A Perspective From A Sunda Village. Bogor (ID) : CGPRT Centre 


\section{LAMPIRAN}

Lampiran 1 Sumbangan input lain kopi Robusta dan Arabika 1. Sumbangan input lain Robusta

\begin{tabular}{|c|c|c|c|c|c|c|c|}
\hline No & Rincian & & & & & & \\
\hline & & \multicolumn{2}{|c|}{ Robusta Honey } & & \multicolumn{3}{|c|}{ Robusta Natural } \\
\hline & & Green bean & Roast bean & Bubuk & Green bean & Roast bean & Bubuk \\
\hline 1 & Listrik dan Air & & 1228,333 & 495 & & $1.228,333$ & 495 \\
\hline 2 & Gas & & 2512,5 & 1012,5 & & $2.512,5$ & $1.012,5$ \\
\hline 3 & Perawatan mesin & 1095 & 10050 & & 730 & 10.050 & \\
\hline 4 & Bensin solar mesin & 183,425 & & & 122,2 & & \\
\hline 5 & Transportasi & 1.215 & 1.935 & 1.350 & 810 & 1.290 & 900 \\
\hline 6 & Kemasan Robusta & & 80.000 & 80.000 & & 80.000 & 80.000 \\
\hline 7 & Plastik & 1.000 & & & 1.000 & & \\
\hline 8 & Lakban & 12.500 & & & 12.500 & & \\
\hline \multirow[t]{4}{*}{9} & Biaya Penyusutan & 58.993 & 9.302 & 464 & 83.868 & 9302 & 464 \\
\hline & Total & 74.986 & 105.027 & 83321 & 99.030 & 104.382 & 82.871 \\
\hline & Jumlah produksi & 100 & 20 & 16 & 100 & 20 & 16 \\
\hline & $\mathrm{Rp} / \mathrm{Kg}$ & 750 & 5.251 & 4.166 & 990 & 5.219 & 4.144 \\
\hline
\end{tabular}

2. Sumbangan input lain Arabika

\begin{tabular}{|r|l|r|r|r|r|r|r|r|r|r|}
\hline No & Rincian & & & & & & & & \\
\hline \\
\hline
\end{tabular}


Lampiran 2 Nilai Tambah Kopi Robusta dan Arabika di KTH Cibulao Hijau

1. Robusta Natural

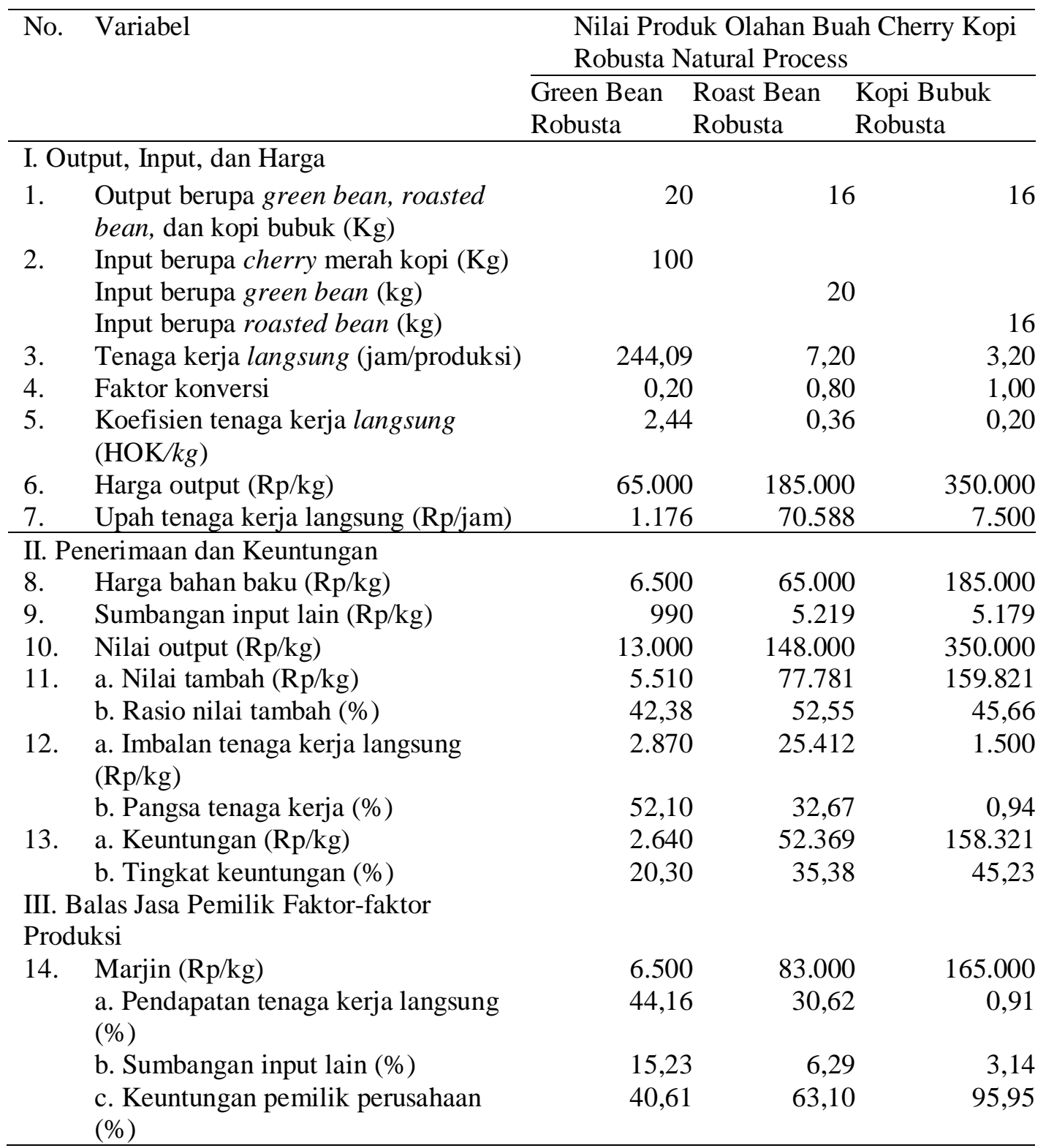


Lampiran 2 Nilai Tambah Kopi Robusta dan Arabika di KTH Cibulao Hijau (Lanjutan)

2. Robusta Honey

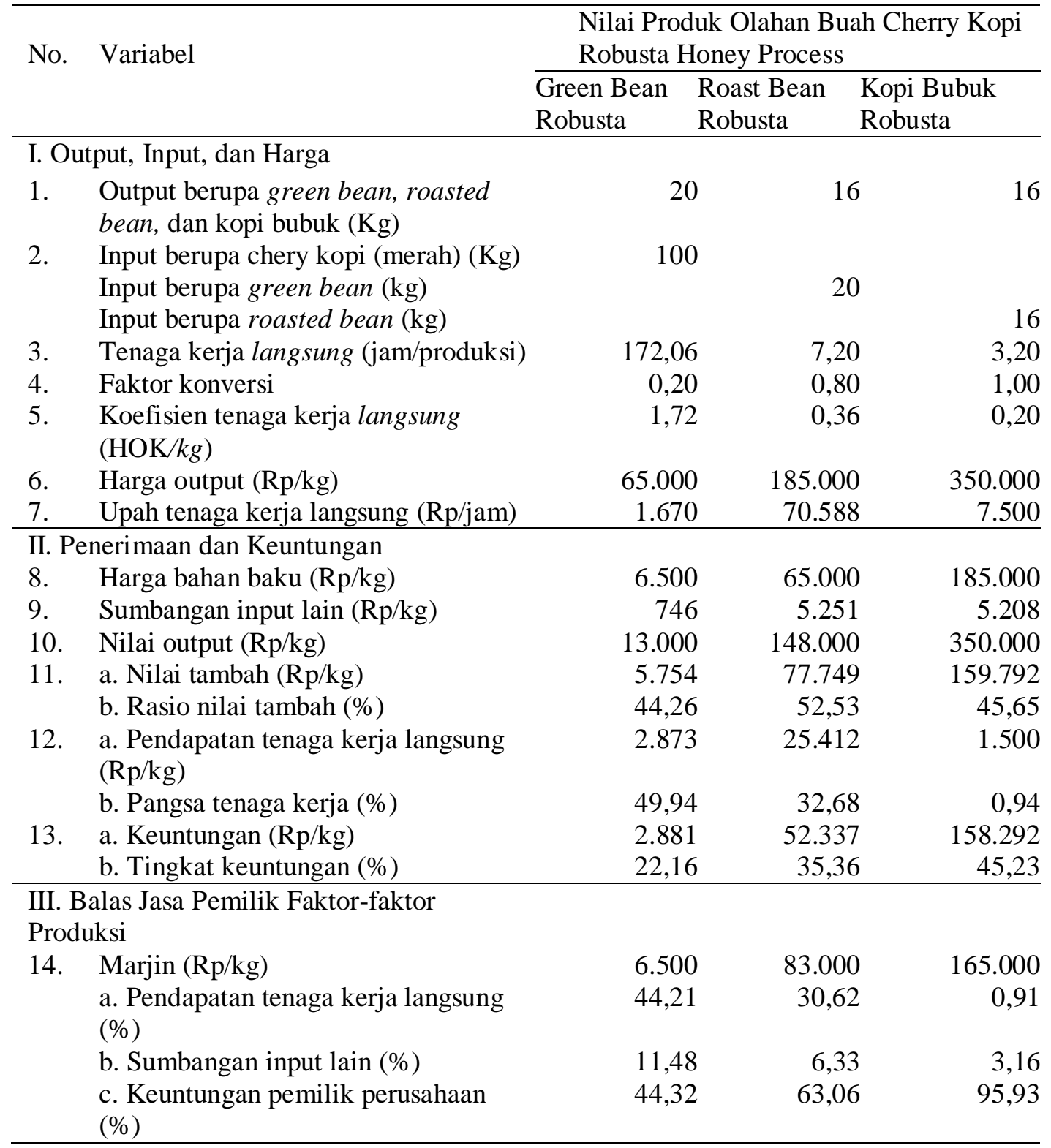


Lampiran 2 Nilai Tambah Kopi Robusta dan Arabika di KTH Cibulao Hijau (Lanjutan)

\section{Arabika Natural}

\begin{tabular}{|c|c|c|c|c|}
\hline \multirow[t]{2}{*}{ No. } & \multirow[t]{2}{*}{ Variabel } & \multicolumn{3}{|c|}{$\begin{array}{l}\text { Nilai Produk Olahan Buah Cherry Kopi } \\
\text { Arabika Natural Process }\end{array}$} \\
\hline & & $\begin{array}{l}\text { Green Bean } \\
\text { Robusta }\end{array}$ & $\begin{array}{l}\text { Roast Bean } \\
\text { Robusta }\end{array}$ & $\begin{array}{l}\text { Kopi Bubuk } \\
\text { Robusta }\end{array}$ \\
\hline \multicolumn{5}{|c|}{ I. Output, Input, dan Harga } \\
\hline 1. & $\begin{array}{l}\text { Output berupa green bean, roasted } \\
\text { bean, dan kopi bubuk (Kg) }\end{array}$ & 14,3 & 11,4 & 11,4 \\
\hline 2. & $\begin{array}{l}\text { Input berupa cheery merah kopi }(\mathrm{Kg}) \\
\text { Input berupa green bean }(\mathrm{kg}) \\
\text { Input berupa roasted bean }(\mathrm{kg})\end{array}$ & 100 & 14,3 & 11,4 \\
\hline 3. & Tenaga kerja langsung (jam/produksi) & 242,66 & 5,2 & 2,3 \\
\hline 4. & Faktor konversi & 0,14 & 0,80 & 1,00 \\
\hline 5. & $\begin{array}{l}\text { Koefisien tenaga kerja langsung } \\
(\mathrm{HOK} / \mathrm{kg})\end{array}$ & 2,43 & 0,36 & 0,20 \\
\hline 6. & Harga output $(\mathrm{Rp} / \mathrm{kg})$ & 135.000 & 380.000 & 460.000 \\
\hline 7. & Upah tenaga kerja langsung (Rp/jam) & 861 & 78.968 & 10.434 \\
\hline \multicolumn{5}{|c|}{ II. Penerimaan dan Keuntungan } \\
\hline 8. & Harga bahan baku (Rp/kg) & 10.000 & 135.000 & 380.000 \\
\hline 9. & Sumbangan input lain $(\mathrm{Rp} / \mathrm{kg})$ & 981 & 4.902 & 5.452 \\
\hline 10. & Nilai output (Rp/kg) & 19.305 & 302.937 & 460.000 \\
\hline \multirow[t]{2}{*}{11.} & a. Nilai tambah $(\mathrm{Rp} / \mathrm{kg})$ & 8.324 & 163.035 & 74.548 \\
\hline & b. Rasio nilai tambah (\%) & 43,12 & 53,82 & 16,21 \\
\hline \multirow[t]{2}{*}{12.} & $\begin{array}{l}\text { a. Imbalan tenaga kerja langsung } \\
(\mathrm{Rp} / \mathrm{kg})\end{array}$ & 2.089 & 28.716 & 2.105 \\
\hline & b. Pangsa tenaga kerja (\%) & 25,10 & 17,61 & 2,82 \\
\hline \multirow[t]{2}{*}{13.} & a. Keuntungan (Rp/kg) & 6.235 & 134.319 & 72.443 \\
\hline & b. Tingkat keuntungan (\%) & 32,30 & 44,34 & 15,75 \\
\hline \multicolumn{5}{|c|}{ III. Balas Jasa Pemilik Faktor-faktor } \\
\hline 14. & Marjin (Rp/kg) & 9.305 & 167.937 & 80.000 \\
\hline & $\begin{array}{l}\text { a. Pendapatan tenaga kerja langsung } \\
(\%)\end{array}$ & 22,45 & 17,10 & 2,63 \\
\hline & b. Sumbangan input lain (\%) & 10,54 & 2,92 & 6,82 \\
\hline & $\begin{array}{l}\text { c. Keuntungan pemilik perusahaan } \\
(\%)\end{array}$ & 67,00 & 79,98 & 90,55 \\
\hline
\end{tabular}


Lampiran 2 Nilai Tambah Kopi Robusta dan Arabika di KTH Cibulao Hijau (Lanjutan)

\section{Arabika Honey}

\begin{tabular}{|c|c|c|c|c|}
\hline \multirow[t]{2}{*}{ No. } & \multirow[t]{2}{*}{ Variabel } & \multicolumn{3}{|c|}{$\begin{array}{l}\text { Nilai Produk Olahan Buah Cherry Kopi } \\
\text { Arabika Honey Process }\end{array}$} \\
\hline & & $\begin{array}{l}\text { Green Bean } \\
\text { Robusta }\end{array}$ & Roast Bean & $\begin{array}{l}\text { Kopi Bubuk } \\
\text { Robusta }\end{array}$ \\
\hline \multicolumn{2}{|c|}{ I. Output, Input, dan Harga } & & & \\
\hline 1. & Output $(\mathrm{Kg})$ & 14,3 & 11,4 & 11,4 \\
\hline \multirow[t]{3}{*}{2.} & Input cherry kopi $\mathrm{n}$ & 100 & & \\
\hline & Input green bean $(\mathrm{kg}$ & & 14,3 & \\
\hline & Input roasted bean $(\mathrm{kg})$ & & & 11,4 \\
\hline 3. & Tenaga kerja lang. & 171,02 & 5,2 & 2,3 \\
\hline 4. & Faktor konversi & 0,14 & 0,80 & 1,00 \\
\hline 5. & $\begin{array}{l}\text { Koefisien tenaga kerja langsung } \\
(\mathrm{HOK} / \mathrm{kg})\end{array}$ & 1,71 & 0,36 & 0,20 \\
\hline 6. & Harga output (Rp/kg) & 115.000 & 370.000 & 460.000 \\
\hline 7. & Upah tenaga kerja langsung (Rp/jam) & 1.222 & 78.968 & 10.434 \\
\hline \multicolumn{5}{|c|}{ II. Penerimaan dan Keuntungan } \\
\hline 8. & Harga bahan baku (Rp/kg) & 10.000 & 115.000 & 370.000 \\
\hline 9. & Sumba & 736 & 5.482 & 5.531 \\
\hline 10. & Nilai & 16.445 & 294.965 & 460.000 \\
\hline \multirow[t]{2}{*}{11.} & a. Nilai $t$ & 5.709 & 174.483 & 84.469 \\
\hline & b. Rasio nil & 34,72 & 59,15 & 18,36 \\
\hline \multirow[t]{2}{*}{12.} & $\begin{array}{l}\text { a. Pendapatan tenaga kerja langsung } \\
(\mathrm{Rp} / \mathrm{kg})\end{array}$ & 2.090 & 28.716 & 2.105 \\
\hline & b. Pangsa tenaga kerja (\%) & 36,61 & 16,46 & 2,49 \\
\hline \multirow[t]{2}{*}{13.} & a. Keuntul & & 145.767 & 82.364 \\
\hline & b. Tingka & 22,01 & 49,42 & 17,91 \\
\hline \multicolumn{5}{|c|}{$\begin{array}{l}\text { III. Balas Jasa Pemilik Faktor-faktor } \\
\text { Produksi }\end{array}$} \\
\hline \multirow[t]{4}{*}{14.} & Marjin (Rp/kg) & 6.445 & 179.965 & 90.000 \\
\hline & $\begin{array}{l}\text { a. Pendapatan tenaga kerja langsung } \\
\text { (\%) }\end{array}$ & 32,43 & 15,96 & 2,34 \\
\hline & b. Sumbangan input lain $(\%$ & 11,42 & 3,05 & 6,15 \\
\hline & c. Keuntungan pemilik perusahaan $(\%)$ & 56,15 & 81,00 & 91,52 \\
\hline
\end{tabular}


Lampiran 2 Nilai Tambah Kopi Robusta dan Arabika di KTH Cibulao Hijau (Lanjutan)

5. Arabika Full wash

\begin{tabular}{|c|c|c|c|c|}
\hline \multirow[t]{2}{*}{ No. } & \multirow[t]{2}{*}{ Variabel } & \multicolumn{3}{|c|}{$\begin{array}{l}\text { Nilai Produk Olahan Buah Cherry Kopi } \\
\text { Arabika Fullwash Process }\end{array}$} \\
\hline & & $\begin{array}{l}\text { Green Bean } \\
\text { Robusta }\end{array}$ & $\begin{array}{l}\text { Roast Bean } \\
\text { Robusta }\end{array}$ & $\begin{array}{l}\text { Kopi Bubuk } \\
\text { Robusta }\end{array}$ \\
\hline \multicolumn{5}{|c|}{ I. Output, Input, dan Harga } \\
\hline 1. & Output $(\mathrm{Kg})$ & 14,3 & 11,4 & 11,4 \\
\hline \multirow[t]{3}{*}{2.} & Input chery kopi merah $(\mathrm{Kg})$ & 100 & & \\
\hline & Input green bean $(\mathrm{kg})$ & & 14,3 & \\
\hline & Input roasted bean $(\mathrm{kg})$ & & & 11,4 \\
\hline 3. & Tenaga kerja langsung (jam/produksi) & 123,02 & 5,2 & 2,3 \\
\hline 4. & Faktor konversi & 0,14 & 0,80 & 1,00 \\
\hline 5. & $\begin{array}{l}\text { Koefisien tenaga kerja langsung } \\
(\mathrm{HOK} / \mathrm{kg})\end{array}$ & 1,23 & 0,36 & 0,20 \\
\hline 6. & Harga output (Rp/kg) & 100.000 & 360.000 & 450.000 \\
\hline 7. & Upah tenaga kerja langsung (Rp/jam) & 1.700 & 78.968 & 10.434 \\
\hline \multicolumn{5}{|c|}{ II. Penerimaan dan Keuntungan } \\
\hline 8. & Harga bahan baku (Rp/kg) & 10.000 & 100.000 & 360.000 \\
\hline 9. & Sumbangan input lain $(\mathrm{Rp} / \mathrm{kg})$ & 565 & 4.902 & 5.452 \\
\hline 10. & Nilai output $(\mathrm{Rp} / \mathrm{kg})$ & 14.300 & 286.993 & 450.000 \\
\hline \multirow[t]{2}{*}{11.} & a. Nilai tambah $(\mathrm{Rp} / \mathrm{k} q$ & 3.735 & 182.091 & 84.548 \\
\hline & b. Rasio & 26,12 & 63,45 & 18,79 \\
\hline \multirow[t]{2}{*}{12.} & $\begin{array}{l}\text { a. Imbalam tenaga kerja langsung } \\
\text { (Rp/kg) }\end{array}$ & 2.091 & 28.716 & 2.105 \\
\hline & b. Pangsa tenaga kerja $(\%)$ & 55,99 & 15,77 & 2,49 \\
\hline \multirow[t]{2}{*}{13.} & a. Keuntungan $(\mathrm{Rp} / \mathrm{kg})$ & 1.644 & 153.375 & 82.443 \\
\hline & b. Tingkat keuntungan $(\%)$ & 11,49 & 53,44 & 18,32 \\
\hline \multicolumn{5}{|c|}{$\begin{array}{l}\text { III. Balas Jasa Pemilik Faktor-faktor } \\
\text { Produksi }\end{array}$} \\
\hline \multirow[t]{4}{*}{14.} & Marjin $(\mathrm{Rp} / \mathrm{kg})$ & 4.300 & 186.993 & 90.000 \\
\hline & $\begin{array}{l}\text { a. Pendapatan tenaga kerja langsung } \\
(\%)\end{array}$ & 48,64 & 15,36 & 2,34 \\
\hline & b. Sumbangan input lain (\%) & 13,14 & 2,62 & 6,06 \\
\hline & c. Keuntungan pemilik perusahaan $(\%)$ & 38,22 & 82,02 & 91,60 \\
\hline
\end{tabular}




\section{Lampiran 3 Analisis Matriks SWOT dalam Strategi Pengembangan Usaha Kopi di KTH Cibulao Hijau}

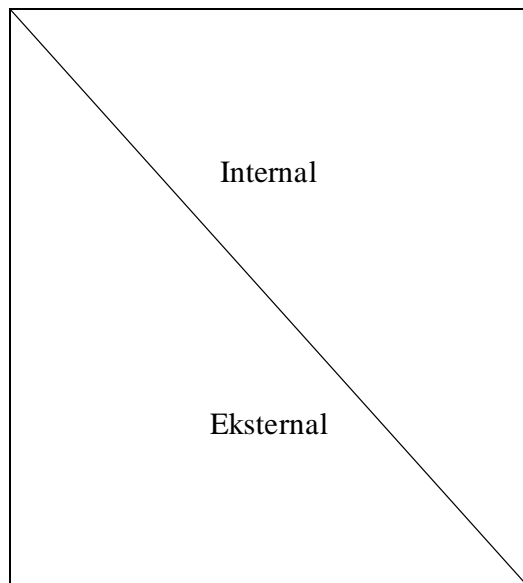

Peluang

1. Kebutuhan dan permintaan kopi yang terus meningkat

2. Pasar kopi spesialti yang terbuka luas baik pasar lokal maupun ekspor

3. Potensi pengembangan wisata edukasi kopi masih terbuka

4. Teknologi informasi dan komunikasi yang semakin canggih

5. Potensi lahan penanaman yang masih cukup

6. Perkembangan teknologi dalam pengolahan kopi yang semakin canggih

7. Semakin banyak petani yang menanam kopi di dalam KTH maupun diluar

8. Banyak pelatihan terkait kualitas produksi kopi, manajerial dan pemasaran kopi

Ancaman

1. Pesaing baru kopi Bogor tumbuh di daerah lain di Bogor

2. Cuaca yang tidak stabil menyebabkan produksi kopi dan kualitas terganggu

3. Kurangnya kesadaran masyarakan tentang perbedaan dan kualitas kopi spesialti

4. Selera konsumen yang berubahubah dan berbeda

5. Pembatasan akses jangkauan dalam proses jual beli produk tanpa legalitas produk
Kekuatan

1. Jenis kopi spesialti dengan kualitas yang baik dan cita rasa khas

2. Harga jual yang tinggi

3. Jenis proses olahan yang beragam

4. Peralatan dan teknologi yang digunakan cukup memadai

5. Memiliki brand image yang dikenal di masyarakat khususnya penggemar kopi

6. Pemberdayaan masyarakat sekitar sebagai SDM di KTH

7. Lokasi usaha strategis karena ada di lokasi wisata

8. Memiliki beberapa pelanggan yang tetap

9. Penanaman kopi berbasis konservasi hutan

Mengoptimalkan pengembangan usaha pengolahan kopi dan wisata edukasi dengan memanfaatkan teknologi informasi dan pengolahan yang semakin canggih (S1, S2, S3, S4, S5, S6, S8, O1, O2, O3, O4, O5,O6)

Mempertahankan dan peningkatan kualitas proses olahan (S1,S2,S3,S4,,S8, T1,T2,T3,T4)

Mengoptimalkan pengelolaan kopi berbasis konservasi sebagai nilai jual dan penguatan positioning KTH (S4,S5,S6,S7, S8,S9,T1,T4)
Kelemahan

1. Belum memiliki PIRT dan Sertifikasi Halal

2. Jumlah produksi dan pasokan masih belum bisa memenuhi permintaan

3. Modal yang terbatas

4. Pengelolaan sistem manajerial $\mathrm{KTH}$ belum optimal

5. Akses jalan menuju KTH kurang memadai

6. Sumberdaya manusia dalam kelompok masih terbatas dan belum terlatih secara optimal

7. Kegiatan promosi belum optimal

Perbaikan dan peningkatan sistem perencanaan pemasaran dan mmperkuat kegiatan promosi (W1, W6, W8, O1, $\mathrm{O} 2, \mathrm{O} 3,04)$

Meningkatkan kompetensi SDM dan kualitas dalam organisasi melalui berbagai pelatihan secara lebih intensif (W4,W6,05,06, O8)

Memperbanyak mitra kerja baik dengan lembaga lainnya serta mengembangkan sistem kemitraan yang telah terjalin. (W2, W3, W5, 06,07,08)

Memperkuat produk yang dihasilkan dengan legalitas usaha dan menjalin hubungan yang baik dengan pelanggan agar terbentuk loyalitas konsumen (W1, $\mathrm{T} 1, \mathrm{~T} 3, \mathrm{~T} 4, \mathrm{~T} 5)$ 